\title{
Transcription factor C/EBP- $\beta$ induces tumor-suppressor phosphatase PHLPP2 through repression of the miR-17-92 cluster in differentiating AML cells
}

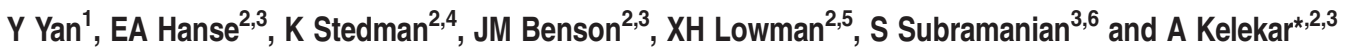

PHLPP2, a member of the PH-domain leucine-rich repeat protein phosphatase (PHLPP) family, which targets oncogenic kinases, has been actively investigated as a tumor suppressor in solid tumors. Little is known, however, regarding its regulation in hematological malignancies. We observed that PHLPP2 protein expression, but not its mRNA, was suppressed in late differentiation stage acute myeloid leukemia (AML) subtypes. MicroRNAs (miR or miRNAs) from the miR-17-92 cluster, oncomir-1, were shown to inhibit PHLPP2 expression and these miRNAs were highly expressed in AML cells that lacked PHLPP2 protein. Studies showed that miR-17-92 cluster regulation was, surprisingly, independent of transcription factors C-MYC and E2F in these cells; instead all-trans-retinoic acid (ATRA), a drug used for terminally differentiating AML subtypes, markedly suppressed miR-1792 expression and increased PHLPP2 protein levels and phosphatase activity. Finally, we demonstrate that the effect of ATRA on miR-17-92 expression is mediated through its target, transcription factor C/EBP $\beta$, which interacts with the intronic promoter of the miR-17-92 gene to inhibit transactivation of the cluster. These studies reveal a novel mechanism for upregulation of the phosphatase activity of PHLPP2 through C/EBP $\beta$-mediated repression of the miR-17-92 cluster in terminally differentiating myeloid cells.

Cell Death and Differentiation (2016) 23, 1232-1242; doi:10.1038/cdd.2016.1; published online 12 February 2016

Phosphatases are pivotal components of intracellular signaling cascades, controlling essential processes like metabolism, apoptosis, proliferation and differentiation. ${ }^{1}$ The $\mathrm{PH}$-domain leucine-rich repeat protein phosphatase (PHLPP) family serine-threonine phosphatases are emerging as central factors in cell survival and death regulation. The PHLPP2 is a member of this family. ${ }^{2,3}$ To date four PHLPP substrates, Akt, PKC, Mst1 and S6K1, have been identified, all kinases involved in cell survival or apoptosis. ${ }^{4-7}$ Dephosphorylation inactivates Akt, S6K1 and PKC, and subsequently cell survival signaling, whereas dephosphorylation of Mst1 activates its apoptotic function.

PHLPP protein expression and activity is suppressed through various mechanisms in cancers. Although most studies on PHLPP2 have focused on genetic alterations in solid tumors, ${ }^{8}$ PHLPP2 protein expression in small cell lung and colorectal cancers is also restricted through translational suppression $^{9}$ and post-transcriptional control by microRNAs (miR or miRNAs), miR-205 and miR-224. ${ }^{10,11}$ The PHLPP2 3' untranslated region (3'UTR) harbors complementary binding sites for a subset of miRNAs belonging to the miRNA-17-92 cluster. ${ }^{12}$ This cluster comprises six miRNAs on chromosome
13, transcribed as a single polycistronic unit. ${ }^{13,14}$ Also known as oncomir-1, the cluster enhances cell proliferation or inhibits apoptosis by suppressing targets such as Bim, E2F1 and PTEN and is markedly overexpressed in human cancers. ${ }^{15-21}$ Reduced levels of PHLPP2 in chemoresistant miR-17-92 overexpressing mantle cell lymphomas had suggested that the phosphatase could be a target of oncomir-1. ${ }^{12}$ Known major activators of the miR-17-92 cluster are transcription factor c-MYC and members of the E2F family, whereas p53 acts as a repressor under hypoxic conditions. ${ }^{22-25}$

As PHLPP2 phosphatases are potential therapeutic targets, it is important to understand mechanisms that regulate PHLPP2 protein expression. Most recent investigations of this tumor-suppressor family have focused primarily on its regulation in solid tumors and their derivative cell lines, rather than in hematological malignancies. The importance of both PHLPP2 and the miR-17-92 cluster in cell survival/apoptosis signaling prompted our investigation of their coordinate regulation in leukemia. The studies described here reveal direct control of PHLPP2 expression through its 3'UTR by the miR-17-92 miRNAs in acute myeloid leukemia (AML) subtypes, and a negative correlation between PHLPP2 protein

${ }^{1}$ Department of Pharmacology, University of Minnesota, Minneapolis, MN, USA ; '2Department of Laboratory Medicine and Pathology, University of Minnesota, Minneapolis, MN, USA; ${ }^{3}$ Masonic Cancer Center, University of Minnesota, Minneapolis, MN, USA; ${ }^{4}$ Biotechnology Program, Minneapolis Community and Technical College, Minneapolis, MN, USA; ${ }^{5}$ Department of Cancer Biology, Beckman Research Institute of City of Hope Cancer Center, Duarte, CA, USA and ${ }^{6}$ Department of Surgery, University of Minnesota, Minneapolis, MN, USA

${ }^{*}$ Corresponding author: A Kelekar, Department of Laboratory Medicine and Pathology, University of Minnesota, 420 Washington Avenue SE, Molecular and Cellular Biology, Room 5-126, Minneapolis, MN 55455, USA. Tel: 612625 3204; Fax: 612626 2600; E-mail: ameeta@umn.edu

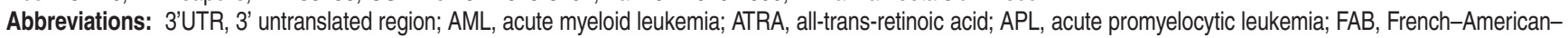
British; miR or miRNA, microRNA

Received 31.7.15; revised 22.11.15; accepted 23.12.15; Edited by SH Kaufmann; published online 12.2.16 
a
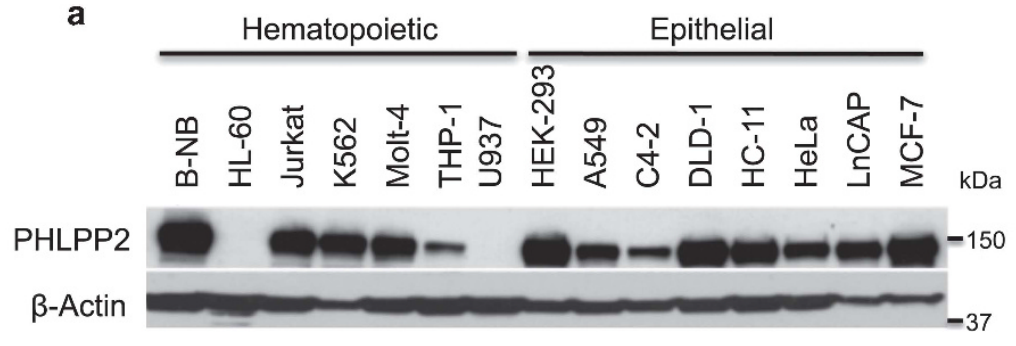

b

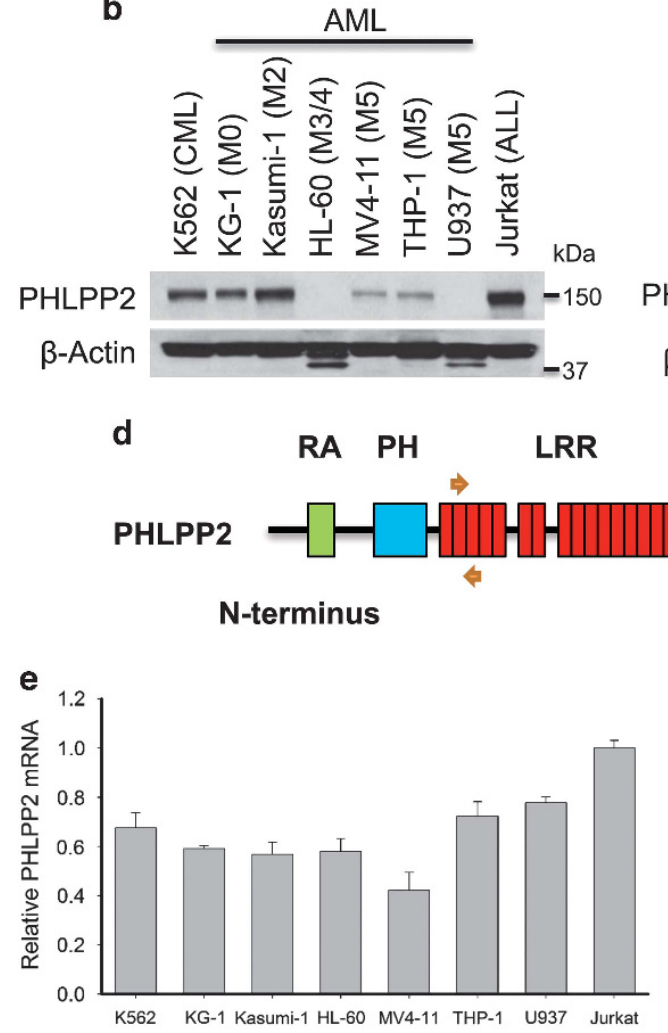

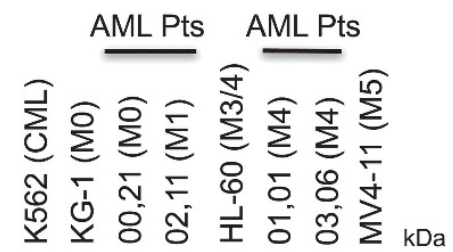

PHLPP2 - - - - -150

$\beta$-Actin

PP2C

PDZ-binding motif

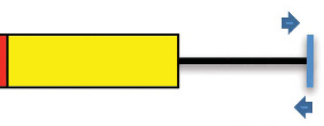

C-terminus

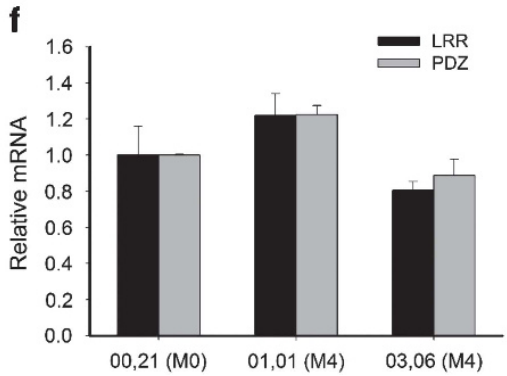

Figure 1 PHLPP2 protein levels are reduced in specific AML subtypes. (a) Western blot (WB) showing PHLPP2 and $\beta$-actin expression in a variety of established hematopoietic and epithelial cell lines (all human except for HC-11). From left to right: B-NB (normal B cells), HL-60 (AML), Jurkat (T-ALL), K562 (CML), Molt-4 (T-ALL), THP-1 (AML), U937 (AML); HEK-293 (human embryonic kidney cells), A549 (lung cancer), C4-2 (prostate cancer), DLD-1 (colorectal cancer), HC-11 (mouse mammary epithelial cells), HeLa (cervical cancer), LnCAP (prostate cancer) and MCF-7 (breast cancer). (b) WB of established AML cell lines (sorted by FAB classification) from left to right: KG-1 (M0), Kasumi-1 (M2), HL-60 (M3), MV4-11 (M5), THP-1 (M5) and U937 (M5). (c) WB of AML patient samples (sorted by FAB classification) from left to right: '00,21' (M0), '02,11' (M1), '01,01' (M4), '03,06' (M5). (d) The PHLPP2 protein domains (not to scale) and locations of PCR primers. Orange primers amplified a region in the LRR domain; blue primers amplified a region within the PDZ-binding motif at the 3 ' end. (e) PHLPP2 mRNA levels were analyzed by real-time PCR (RT-PCR) using the PDZ primers as shown in d. PHLPP2 mRNA levels in each of the cell lines shown were normalized to those in Jurkat cells. (f) PHLPP2 mRNA levels in representative AML patient samples, 00,21 (M0), 01,01 (M4) and 03,06 (M4), were detected by RT-PCR. PHLPP2 mRNA levels in 01,01 and 03,06 were normalized to those in 00,21

and miR-17-92 cluster levels in these cancers. These studies also identify a novel pathway for upregulation of the phosphatase through repression of the oncomir-1 cluster by $C / E B P \beta$, an all-trans-retinoic acid (ATRA)-induced transcription factor.

\section{Results}

PHLPP2 protein is poorly expressed or absent in specific AML subtypes. We compared PHLPP2 protein levels in a variety of human myeloid and lymphoid leukemia cell lines with those in cell lines derived from solid tumors (Figure 1a).
Western blots revealed a range of expression, with immortalized $B$ cells (B-NB) showing the highest levels. In three AML cell lines, THP-1, HL-60 and U937, PHLPP2 protein levels were greatly reduced or absent (Figure 1a). Under the French-American-British (FAB) classification system there are eight $A M L$ subtypes, $M 0-M 7$, classified by myeloid lineage and degree of differentiation of the leukemia cells. ${ }^{26}$ THP-1 and U937 are M5 subtypes, whereas HL-60 is classified as an M3 AML (promyelocytic leukemia) and, more recently, as an M4 AML (myelomonocytic) subtype. Figure 1b shows that the PHLPP2 protein was suppressed in the more differentiated (M3/M4 and M5) AML, whereas levels in M0 
and M2 lines were comparable to those in K562, a chronic myeloid leukemia (CML) and Jurkat, a T-cell acute lymphocytic leukemia (T-ALL). These observations were further supported by PHLPP2 western blots of patient cells of $\mathrm{M} 0$, M1 and M4 AML subtype (Figure 1c).

As PHLPP2 is deleted or mutated at a high frequency in solid tumors, ${ }^{8}$ we checked The Cancer Genome Atlas database $e^{27,28}$ to determine whether the poor expression of PHLPP2 in AML was also due to gene mutation or deletion. Our analysis revealed that, compared with breast and prostate tumors, the PHLPP2 gene was rarely altered in AML, with no mutations and a deletion rate of $<3 \%$ (Supplementary Figure $\mathrm{S} 1 \mathrm{~A})$. Moreover, there was only one deep deletion and eight instances of upregulated transcripts in a total of $166 \mathrm{AML}$ patient samples in the database (Supplementary Figure S1B), suggesting that gene alteration was unlikely to account for poor expression of PHLPP2 proteins in these cancers.

We checked whether the observed low PHLPP2 protein expression correlated with PHLPP2 mRNA levels using primer pairs that amplified different regions of the $3.9 \mathrm{~kb} P H L P P 2$ transcript (Figure 1d). PHLPP2 mRNA was detected by Q-PCR or steady-state RT-PCR using either the 5' LRR primer or 3' PDZ-ligand sets (Supplementary Figure S1D, Figure 1 e and Supplementary Figure S1C) in all the AML lines. mRNA levels in the M5 lines, where PHLPP2 protein levels ranged from low to absent (Figure $1 \mathrm{~b}$ ), were comparable to those in high PHLPP2 protein-expressing K562 or Jurkat cells (Figures $1 \mathrm{~b}$ and $\mathrm{c}$ ). Notably, PHLPP2 mRNA levels in three AML patient samples tested, 00,21 (M0 with detectable PHLPP2 protein, Figure 1c), and 01,01 or 03,06 (M4 with lower PHLPP2 protein, Figure 1c), were also comparable (Figure $1 f$ and Supplementary Figure S2A). The half-life of PHLPP2 transcripts was similar in both high and low expressing leukemia cell lines (Supplementary Figure S2B), ruling out mRNA degradation as the reason for suppression of PHLPP2 protein in specific AML subtypes. We also treated HL-60 and U937 cells with MG132 and bortezomib to check for increased proteasomal degradation of PHLPP2 protein, as reported previously. ${ }^{29}$ Neither proteasome inhibitor increased PHLPP2 protein expression in the AML cell lines (Supplementary Figure S2C). Thus, the data in, Figure 1 pointed to a significant reduction in PHLPP2 protein levels in specific AML subtypes (M3-M5) via a post-transcriptional mechanism.

The oncomiR-17-92 cluster controls PHLPP2 protein levels in AML. We investigated the possibility that miR-1792 was regulating translation of the PHLPP2 messenger in AML. The PHLPP2 3'UTR harbors complementary binding sites for a subset of miRNAs, miR-17, 19, 18a, 20a and 92a, of the miRNA-17-92 cluster (Figure 2a). PHLPP2 was previously shown to be responsive to miR-17-92 miRNAs in transfected HEK-293 cells. $^{12}$ Our data showed clear negative correlation between PHLPP2 protein levels and miRNA-17-92 levels in AML cell lines and patient samples. Three M5 cell lines with reduced PHLPP2 protein (Figure 1b) had higher levels of miR-17-92 transcripts than Jurkat cells (Figure 2b). In addition, levels of all individual miR-17-92 miRNAs in M4 patient cells were higher than those in an M0 patient sample (Figure 2c).
To further confirm that miRNA-17-92 transcripts were key regulators of PHLPP2 mRNA in AML, we checked the ability of a tetracycline-inducible construct, expressing three shRNAs against the primary miR-17-92 cluster transcript (Supplementary Methods), to induce expression of PHLPP2 and of known miRNA-17-92 target, Bcl-2 protein Bim. ${ }^{15}$ Levels of both proteins were increased in cells transfected with the shRNA (Figure 2d), and these were further upregulated by increasing concentrations of doxycycline (Dox) in HEK-293 cells. The inhibitor construct also enhanced Bim and PHLPP2 protein expression in HL-60 and U937 cells (Figure 2e). Thus, inhibition of miR-17-92 in AML cells could reverse the suppression of PHLPP2 translation. Attempts to further increase expression with Dox treatment resulted in rapid apoptosis of the AML transfectants (data not shown), suggesting these cells were sensitive to increased levels of miR-17-92 targets.

To assess the ability of the PHLPP2 3'UTR to upregulate PHLPP2 protein by acting as a sponge for miR-17-92 transcripts, we cloned the 3'UTR of PHLPP2 from the genomic DNA of 01,01 (M4) AML patient cells into an expression vector. PHLPP2 protein levels increased in a concentrationdependent manner with increasing amounts of the 3'UTR construct in transiently transfected HEK-293 cells (Figure 2f). The strategy for checking expression of the 3'UTR while differentiating between the endogenous and transfected 3'UTR transcripts using 'Internal' and 'Overlap' primers is detailed under Supplementary Figure S3B. Supplementary Figure S3C shows that stably transfected HL-60 (M3/M4) and U937 (M5) cells expressed higher levels of the internal 3'UTR fragment than control transfectants (CV). Importantly, expression of this exogenous 3'UTR caused upregulation of PHLPP2 proteins, particularly in HL-60 cells (Figure $2 \mathrm{~g}$ and Supplementary Figure S3A) without affecting PHLPP2 transcript levels in stably transfected cells (Supplementary Figure S3D). Finally, to confirm the specificity of the PHLPP2 3'UTR as a miR-17-92 sponge, we mutated all miR-17-92 miRNA binding sites in the 3'UTR construct (Figure 2a). The mutated 3'UTR construct no longer induced PHLPP2 expression in either HEK-293 or HL-60 cells (Figure 2g). Interestingly, the 3'UTR-transfected HL-60 cells with higher PHLPP2 expression showed a slower growth rate than controls (Supplementary Figure S3E). These results suggest that the miR-17-92 cluster is a major regulator of PHLPP2 protein expression in AML.

Expression of miRNA-17-92 cluster in AML is not controlled by transcription factors C-MYC or E2F. The miR-17-92 cluster was reported to be directly activated by the c-MYC oncogene or E2F transcription factors in a cell type-specific manner. ${ }^{14,22-24}$ We checked whether either of these transcription factors was controlling PHLPP2 expression through miR-17-92 in AML cells. First, silencing c-myc in HL-60 cells (Figure 3a) showed no significant effect on the miR-17-92 primary transcript (Figure 3b), individual mature miRNAs belonging to miR-17-92 cluster (Figure 3c) or on PHLPP2 protein levels (Figure 3d). The reduction in Bim protein expression following loss of c-myc, is likely due to the direct regulation of Bim by c-myc rather than miR-17-92. ${ }^{30}$ Similarly, c-myc silencing affected neither miR-17-92 

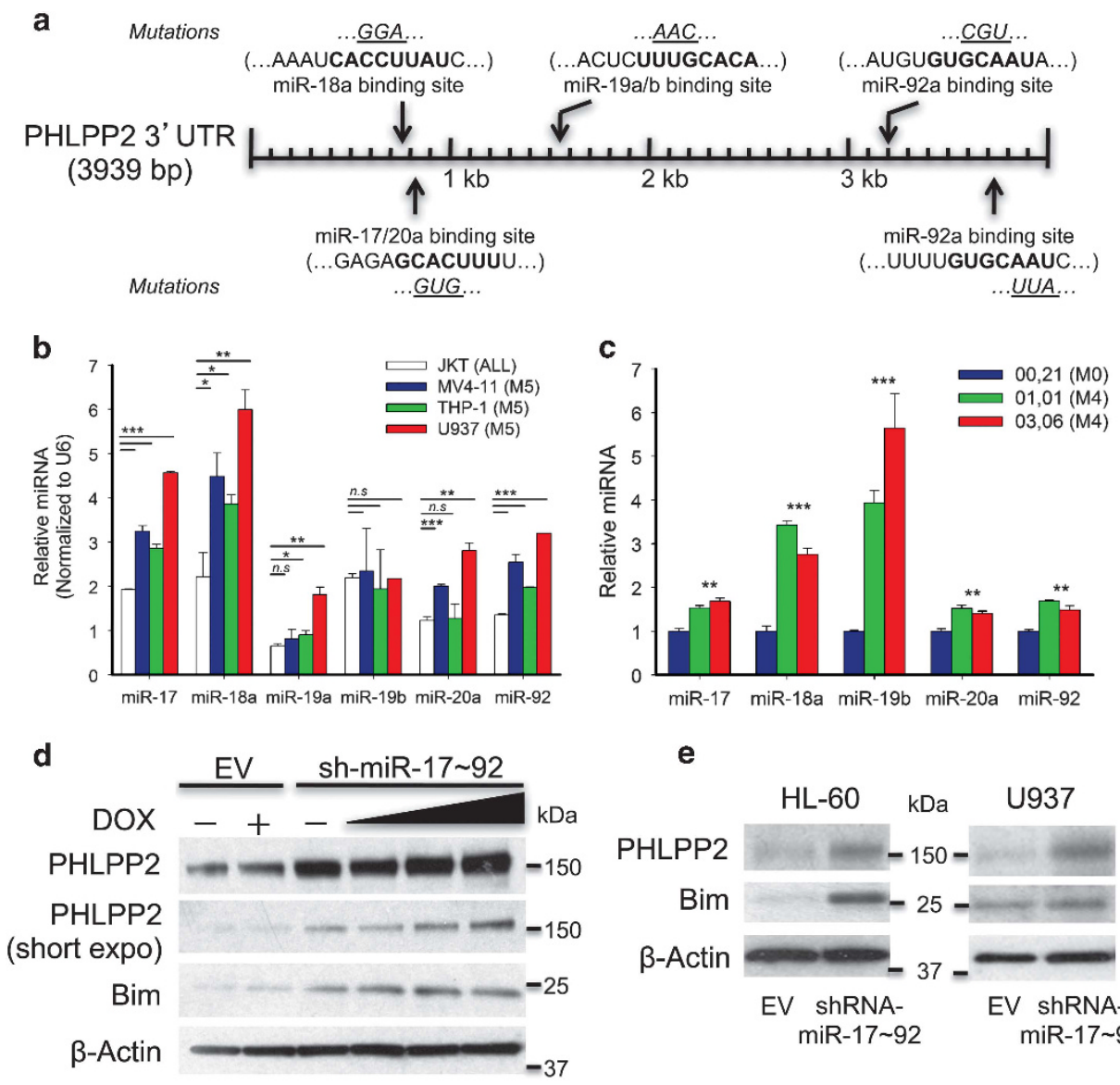

e
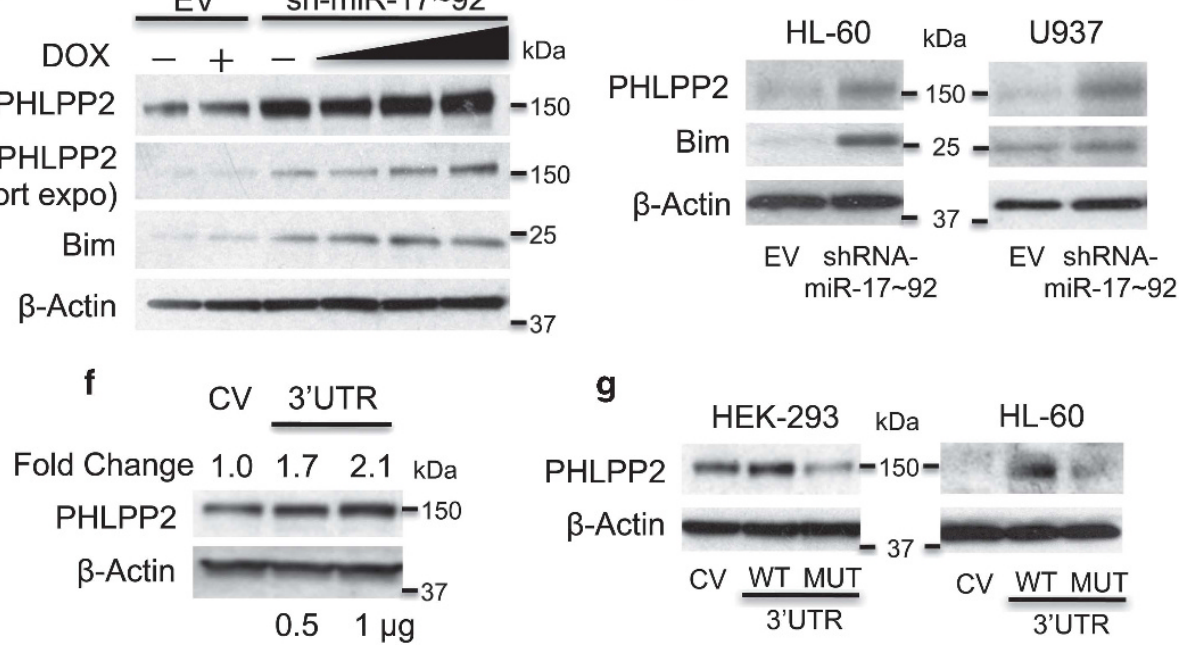

Figure 2 PHLPP2 protein expression is regulated by the miRNA-17-92 cluster in AML cell lines and patient samples. (a) PHLPP2 (3939 bp) 3'UTR showing binding sites for miRNAs from the miRNA-17-92 cluster. Each specific sequence that binds to the miRNA seed sequence within these sites is shown in bold. The mutations for each binding site (three-nucleotide mutation) are shown in underlined italics. (b) Expression of miRNAs, miR-17, -18a, -20a, -92 and -19, from the miR-17-92 cluster was quantified in the indicated cell lines using the miR-17-92 plate assay kit (Signosis Inc.). Values were normalized to internal control, U6, in each cell line. NS represents no significant difference; ${ }^{*} P<0.05$; ${ }^{* \star} P<0.01 ;{ }^{* \star \star} P<0.001$. (c) miR-17-92 cluster levels were quantified in the indicated M0 and M4 AML subtype patient samples using the Signosis plate assay. (d) WBs of lysates from HEK-293 cells transfected with $2 \mu \mathrm{g}$ TripZ-shRNA-miRNA-17-92 (sh-miR-17-92) or empty vector (EV), treated with $1 \mu \mathrm{g} / \mathrm{ml}$ Dox for EV or $0.3 \mu \mathrm{g} / \mathrm{ml}, 1 \mu \mathrm{g} / \mathrm{ml}, 3 \mu \mathrm{g} / \mathrm{ml}$ Dox for sh-miR-17-92 $24 \mathrm{~h}$ post-transfection and harvested $48 \mathrm{~h}$ later. (e) WBs of lysates prepared from HL-60 or U937 cells transfected with $3 \mu \mathrm{g}$ TripZ-empty vector (EV) or TripZshRNA-miRNA-17-92 (shRNA). Viable cells were purified by gradient centrifugation within $24 \mathrm{~h}$ and harvested $48 \mathrm{~h}$ later. (f) Expression of PHLPP2 in immunoblots of HEK-293 cells $72 \mathrm{~h}$ after transfection with the indicated concentrations of pcDNA3.1 plasmid (control vector, CV), or PHLPP2 3'UTR constructs. The PHLPP2 bands were analyzed by densitometry and normalized to the corresponding $\beta$-actin band. (g) Expression of PHLPP2 in HEK-293 cells and HL-60 cells after transfection with pcDNA3.1 plasmid (CV), wildtype 3'UTR construct (WT) or mutant 3'UTR construct (MUT)

transcript nor PHLPP2 protein levels in U937 AML and K562 $\mathrm{CML}$ cells (Supplementary Figures S4A and C). We also used siRNA to silence E2F1 and E2F3 expression, individually or together, in HL-60 cells (Figure 3e). Again, miR-17-92 primary transcript (Figure $3 f$ ) and mature miRNA levels (data not shown) were unaffected, indicating that E2F did not control this miRNA cluster in AML. PHLPP2 protein expression also remained unchanged (Figure $3 e$ ). We conclude that regulation of both the miR-17-92 cluster and subsequent
PHLPP2 expression levels were independent of c-myc and E2F transcriptional factors in AML and, possibly, in other types of myeloid leukemia.

ATRA-induced granulocytic differentiation in promyelocytic AML is accompanied by PHLPP2 induction and suppression of the miR-17-92 cluster. The proliferation of HL-60 cells is slowed on exposure to ATRA, and activates their terminal differentiation into granulocytes, ${ }^{31-34}$ shown in 
a

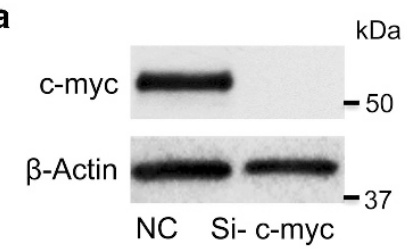

C

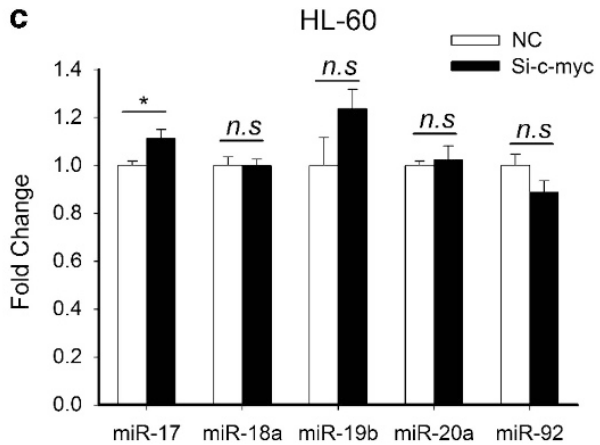

b miR-17 92 primary transcript level
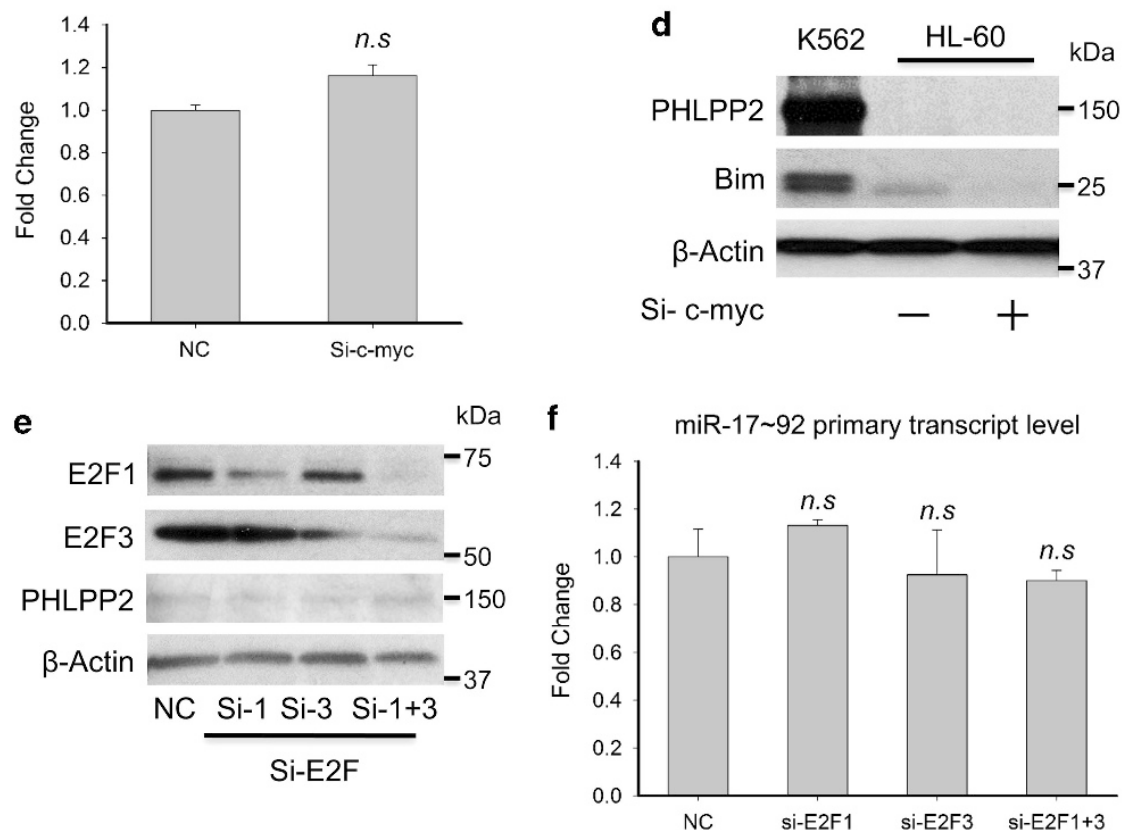

Figure 3 Expression of miRNA-17-92 cluster in AML is not controlled by transcription factors c-MYC or E2F. (a) WBs showing c-myc levels in HL-60 cells $72 \mathrm{~h}$ after transfection with c-mycsiRNAor control siRNA (NC). (b) RT-PCR quantification of miRNA-17-92 primary transcript levels in HL-60 cells. n.s - no significant difference. (c) RT-PCR quantification of individual mature miRNAs from the miRNA-17-92 cluster in the transfected $\mathrm{HL}-60$ cells shown in a. miRNA levels were first normalized to the internal control U6 and then individual miRNA levels in si-c-myc cells were further normalized against the negative controls; ${ }^{*} p<0.05 ; n$.s - no significant difference. (d) PHLPP2 and Bim protein levels in WBs of HL-60 cells $72 \mathrm{~h}$ after transfection with c-myc or control siRNAs. PHLPP2 protein expression in K562 cells was used as a positive control for the PHLPP2 band on the blot. (e) WBs showing E2F and PHLPP2 protein levels in HL-60 cells silenced for E2F1 or E2F3 expression, or both, along with negative control, NC. (f) Fold change in miRNA-17-92 primary transcript levels in HL-60 cells silenced for E2F1 or E2F3 expression individually or together, $72 \mathrm{~h}$ after transfection of the siRNA. n.s - no significant difference

Supplementary Figures S5A and B. Based on our observation that PHLPP2 3'UTR-transfected HL-60 cells had a reduced growth rate compared with control vectortransfected cells (Supplementary Figure S3E), we asked whether PHLPP2 levels changed during ATRA-induced differentiation and whether this effect was mediated through the miR-17-92 cluster. Figure 4a shows that PHLPP2 protein was markedly induced upon treatment of HL-60 cells with ATRA for $3-5$ days. Cell surface differentiation marker CD11b correspondingly increased in a concentration- and timedependent manner (Figure 4b). We also detected a reduction in Thr389 phosphorylation of pS6K, a major PHLPP2 substrate, in cells exposed to ATRA for 3 days (Figure 4c). However, phosphorylation of Akt Ser473, a second PHLPP2 target, increased (Supplementary Figure S5C). These results were consistent with published studies showing Akt was phosphorylated and activated following ATRA treatment ${ }^{35}$ and suggested that pS6K was the primary target of PHLPP2 during ATRA-induced differentiation. In addition, ATRA had no effect on PHLPP2 mRNA levels (Figure 4d), whereas miR-17-92 cluster family members decreased by almost $50 \%$ in HL-60 cells in 3 days (Figure 4e). Consistent with the reduction in individual miRNA levels, the primary cluster transcript also decreased with ATRA treatment (Supplementary Figure S5D), confirming that ATRAmediated differentiation inhibits transactivation, rather than processing, of the cluster. Coordinate changes in PHLPP2 and miR-17-92 expression levels during ATRA-induced differentiation offered further evidence of post-transcriptional inhibition of PHLPP2 by the miR-17-92 cluster and supported 
PHLPP2

$\mathrm{kDa}$

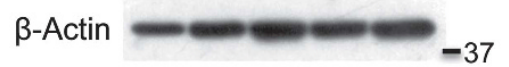

ATRA

$$
\text { Con } \frac{3 D}{0.1 \mu M} \frac{3 D 5 D}{1 \mu M}
$$

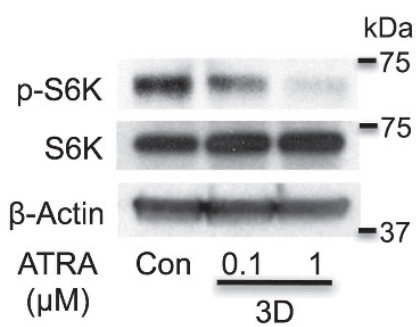

d

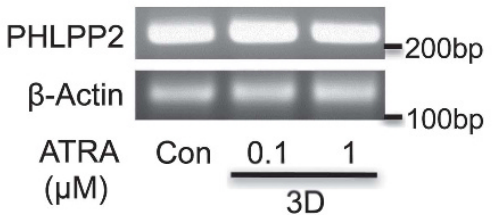

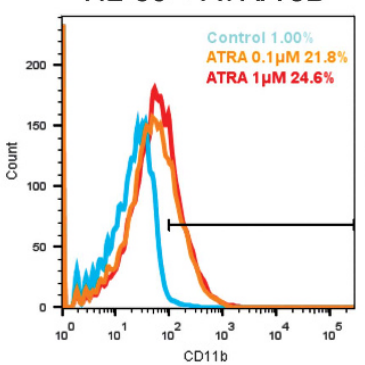

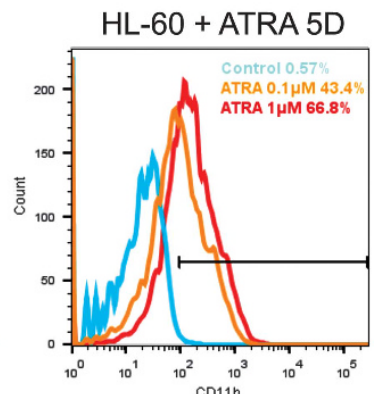

e

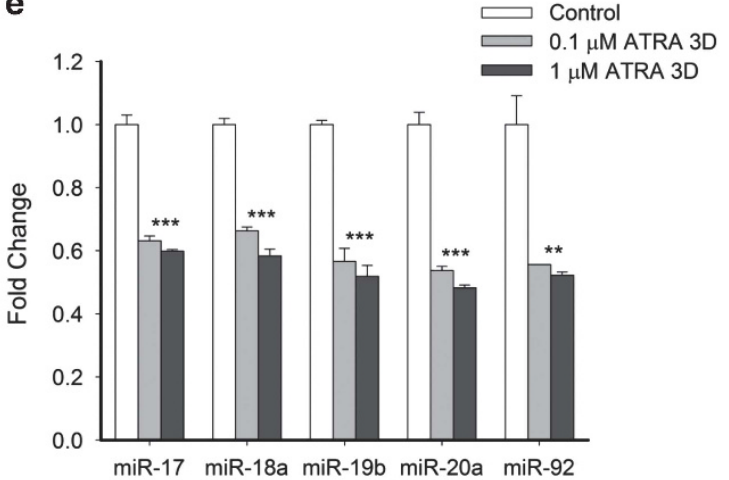

f

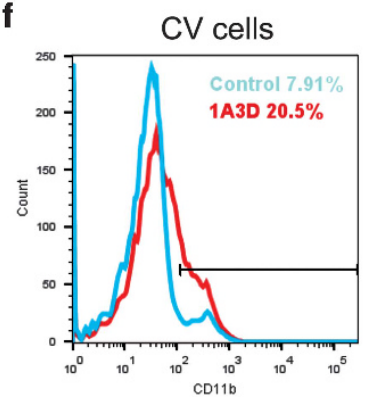

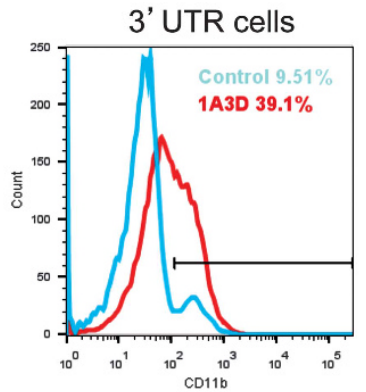

h

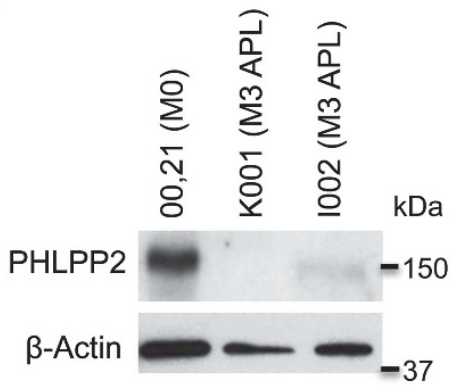

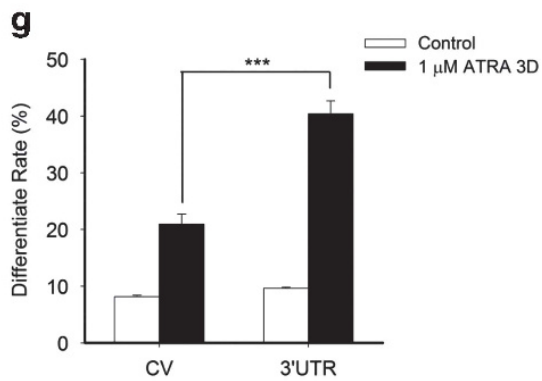

i

Figure 4 ATRA induces PHLPP2 expression by suppressing the miR-17-92 cluster during granulocytic differentiation. (a) WBs showing PHLPP2 protein levels in HL-60 cells induced to differentiate in the presence of ATRA. (b) Differentiation of HL-60 cells treated with 0.1 or $1 \mu \mathrm{M}$ ATRA for 3 days or 5 days was monitored through flow cytometric detection of CD11b. (c) Thr ${ }^{389} \mathrm{~S} 6 \mathrm{~K}$ phosphorylation levels were reduced in HL-60 cells treated with 0.1 or $1 \mu \mathrm{M}$ ATRA for 3 days. (d) PCR analysis of PHLPP2 mRNA in ATRAtreated HL-60 cells. (e) miRNA-17-92 cluster levels in response to ATRA treatment. Individual miRNAs from ATRA-treated cells and controls were quantified through RT-PCR and normalized to the internal control U6. Shown in the graph is the fold change in individual miRNA levels in ATRA-treated cells compared with untreated controls; ${ }^{* *} p<0.01$; ${ }^{* * *} p<0.001$. (f) Rate of differentiation of pcDNA3.1 (CV) and $3^{\prime} U T R$-transfected HL-60 cells treated with $1 \mu$ M ATRA for 3 days was monitored by detection of the surface marker $\mathrm{CD} 11 \mathrm{~b}$. Shown are representative data from one of three independent experiments. The results from the three experiments are quantified in $(\mathbf{g}) ;{ }^{* * *} p<0.001$. (h) WBs showing PHLPP2 protein levels in two APL patient samples and an M0 AML patient sample. (i) Individual miRNA-17-92 cluster transcript levels in four patient samples were quantified using RT-PCR and plotted as a fold change compared with levels in the MO patient cells 
the hypothesis that this regulation occurred through an ATRAmediated signaling pathway.

The reduced inhibition of PHLPP2 expression by the miR-17-92 cluster during ATRA treatment, suggests this could be a primary mode of action of the drug. Moreover, the increased rate of differentiation of HL-60 cells stably overexpressing the PHLPP2 3'UTR in response to ATRA (Figures $4 \mathrm{f}$ and $4 \mathrm{~g}$ ) support this possibility. Thus, ATRA exerts its function partly by reversing the oncomir-1-mediated posttranscriptional inhibition of PHLPP2.

We also compared PHLPP2 protein expression and miR-17-92 cluster levels in cells from acute promyelocytic leukemia (APL; M3) patients with those of a less mature (M0) AML patient sample. Both APL patient samples tested expressed substantially reduced levels of PHLPP2 protein (Figure 4h). Furthermore, all four APL samples tested had higher expression of individual miRNAs from the miR-17-92 cluster than MO AML cells (Figure 4i). The consistently negative correlation between PHLPP2 protein levels and miR-17-92 transcripts in APL patient samples underscores the physiological relevance of this regulatory pathway.

Transcription factor C/EBP $\beta$, induced by ATRA, represses the miR-17-92 cluster through interactions with its intronic promoter. ATRA activates the expression of a number of target genes involved in myeloid cell differentiation through interaction with nuclear receptor and transcription factor retinoic acid receptor a (RARa). ${ }^{36,37} \mathrm{~A}$ scan of the region upstream of the miR-17-92 cluster revealed putative binding sites for CCAATT enhancer binding protein and transcription factor family member, C/EBP $\beta$, a major ATRA target. The activation of $\mathrm{C} / \mathrm{EBP} \beta$ is an early event in the ATRA-induced differentiation response. ${ }^{38,39} \mathrm{We}$ first determined the concentration- and time-dependent induction of C/EBP $\beta$ in the HL-60 cell line (Figure 5a). Transfection of C/EBP $\beta$ siRNA abrogated the drug's ability to upregulate $\mathrm{C} / \mathrm{EBP} \beta$ protein levels (Figure $5 \mathrm{~b}$ ) and slowed the rate of ATRA-induced differentiation in the HL-60 cells (Figure 5c). Both miR-17-92 primary transcript and mature miRNA levels were reduced in control siRNA expressing HL-60 cells exposed to ATRA, but not in C/EBP $\beta$-silenced cells (Figures $5 d$ and e), suggesting that the ATRA-induced downregulation of the cluster was dependent on C/EBP $\beta$. The decreased miR-17-92 transcripts in the untreated $\mathrm{C} /$ EBP $\beta$ knockdown cells remained unresponsive to ATRA and suggest an additional, ATRA-independent mechanism for control of the miRNA cluster by C/EBP $\beta$. PHLPP2 protein was also suppressed in the C/EBP $\beta$-silenced HL-60 cells following ATRA treatment (Figure $5 f$ ).

The miR-17-92 cluster is an intronic cluster, reported to harbor intronic miRNA promoters. ${ }^{40}$ ATFSEARCH scan of the region 3000 nucleotides upstream of the miR-17-92 cluster identified two response elements matching the C/EBP $\beta$ DNA binding consensus sequence $R$ TTGCGYAAY, ${ }^{41}$ roughly $600 \mathrm{bp}(-609$ to -600$)$ and $1050 \mathrm{bp}(-1051$ to -1042$)$ upstream of mir-17-92, respectively (Figure 6a). To determine whether C/EBP $\beta$ bound directly to any of these putative response elements, we performed a chromatin immunoprecipitation (ChIP) assay. We designed two PCR amplicons for the putative binding sites and a third for a region without C/EBP $\beta$ - binding sites. C/EBP $\beta$ was enriched at the distal but not at the proximal promoter region, following ATRA treatment (Figure 6b). Furthermore, RNA polymerase (pol) II was enriched at this region in untreated cells, but not detected following ATRA treatment. The replacement of RNA pol II at this site by ATRA-induced C/EBP $\beta$ supports our hypothesis that the transcription factor inhibits miR-17-92 transcription. We also detected some, albeit weaker, C/EBP $\beta$ interaction with the second predicted $(-600 \mathrm{bp})$ element upon ATRA treatment. Although we cannot rule out the presence of $\mathrm{C} /$ EBP $\beta$ at the proximal promoter, we may be detecting distal binding with proximal probes, given the short distance ( $450 \mathrm{bp}$ ) between the two regions. Regardless, our data strongly support a repressive function for C/EBP $\beta$ at the distal promoter. Figure $6 \mathrm{c}$ shows quantitatively that the interaction between RNA pol II with Amplicon 1 was significantly reduced and interaction of $\mathrm{C} / \mathrm{EBP} \beta$ with this site increased following ATRA treatment (Figure $6 \mathrm{c}$ ). These data demonstrate that $\mathrm{C} /$ EBP $\beta$ interacts directly with the miR-17-92 intronic promoter and, more importantly, that this interaction represses the transcription of this oncomir. Together with our previous observations (Figure 3), the ChIP assay provides strong evidence supporting our hypothesis that transcription factor $\mathrm{C} /$ $\mathrm{EBP} \beta$, rather than c-MYC or E2F, regulates miR-17-92 cluster expression in AML.

\section{Discussion}

PHLPP phosphatases have emerged as central factors in the signaling pathways that antagonize both cell survival and the cancer phenotype. ${ }^{8}$ Here we demonstrate that the phosphatase, PHLPP2, is suppressed in AML subtypes, M3, M4 and M5, by miRNAs belonging to the miR-17-92 cluster, oncomir-1. We also show that the phosphatase is significantly upregulated in cells induced toward granulocytic differentiation by ATRA, a drug used for treating AML, through repression of the miR-17-92 cluster. Finally, we demonstrate a novel role for transcription factor C/EBP $\beta$, a mediator of ATRA-induced differentiation, in direct repression of the miR-17-92 cluster leading to upregulation and activation of PHLPP2. Our findings are summarized in a model in Figure 7.

A majority of the PHLPP substrates are oncogenic kinases central to growth and proliferation, such as AKT, S6K and PKC. ${ }^{4,6}$ As a tumor suppressor PHLPP is deleted in many cancers, whereas others show reduced mRNA and protein levels. Studies on PHLPP family proteins have focused on solid tumors, such as prostate, colorectal and breast cancers, as well as melanomas and non-small cell lung cancers. ${ }^{8}$ We show, for the first time, that PHLPP2 is suppressed in more differentiated AML subtypes, M3-M5, identified based on the FAB classification. The FAB system ${ }^{26}$ sorts $A M L$ on the basis of morphology, cell type and degree of differentiation in contrast to the broader WHO classification, which takes into account factors that impact prognosis. Our studies show differential expression of PHLPP2 in specific AML subtypes and reveal a novel mechanism for repression and de-repression of PHLPP2 suggesting its potential as a biomarker and therapeutic target. Differential expression of the miR-17-92 cluster across FAB subtypes also suggests developmental regulation. 

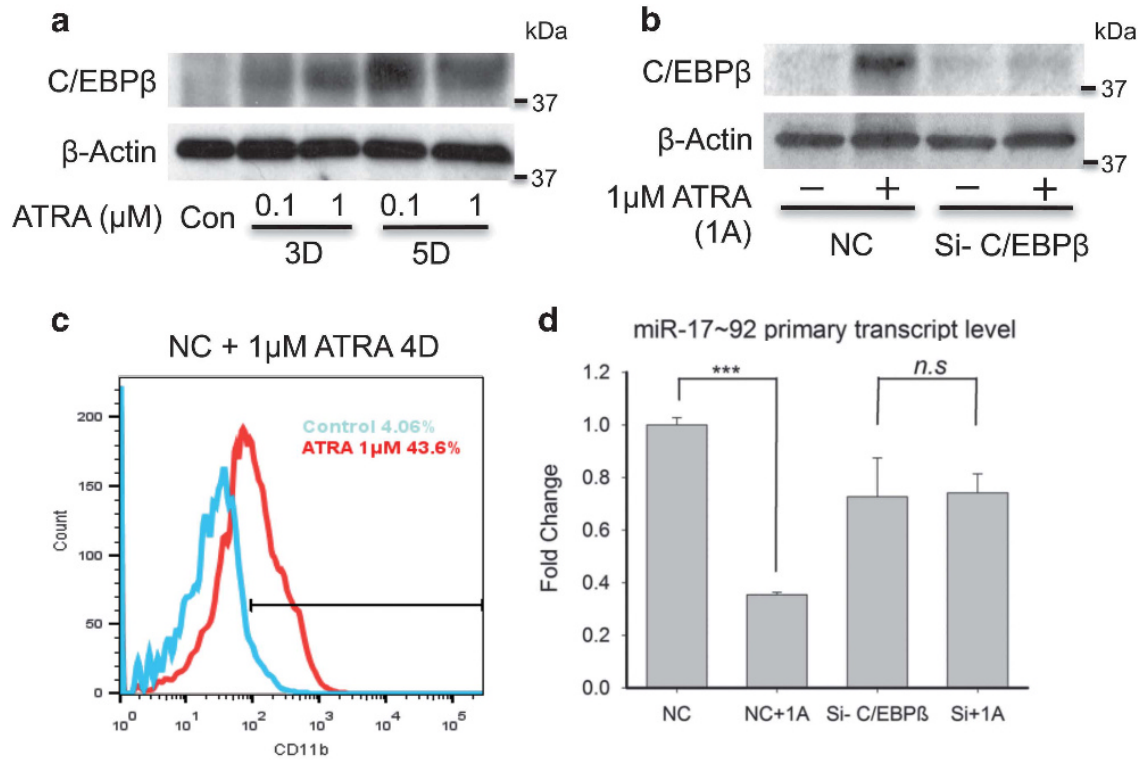

d

miR-17 92 primary transcript level
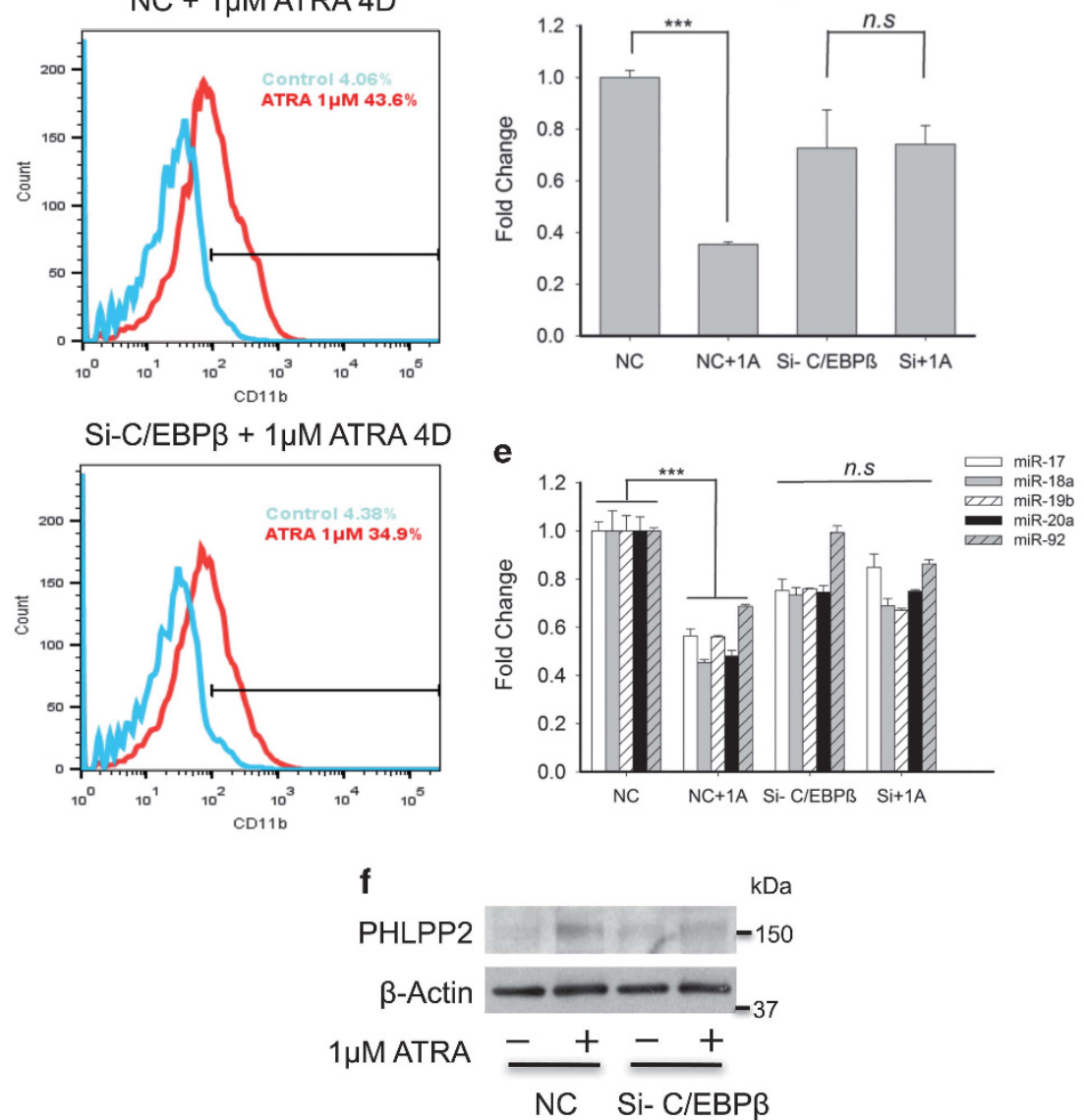

Figure 5 ATRA induced downregulation of the miR-17-92 cluster is mediated through transcription factor C/EBP $\beta$. (a) WBs showing C/EBP $\beta$ protein levels in HL-60 cells treated with two concentrations of ATRA for 3 and 5 days. (b) HL-60 cells were transfected with C/EBP $\beta$ and control siRNA. After $24 \mathrm{~h}$, cells were treated with $1 \mu \mathrm{M}$ ATRA for 3 days. Induction of C/EBP $\beta$ and efficiency of silencing was confirmed by WB. (c) C/EBP $\beta$ silenced cells and controls were treated with $1 \mu \mathrm{M}$ ATRA for 4 days and appearance of the differentiation marker CD11b was detected by flow cytometry. Shown are representative data from three independent experiments. (d) C/EBP $\beta$ silencing reverses the suppressive effect of ATRA on the miR-17-92 cluster. siRNA transfected cells were treated with $1 \mu \mathrm{M}$ ATRA for 3 days and miR-17-92 primary transcript levels were quantified by RT-PCR. n.s - no significant difference; ${ }^{* *} p<0.001$. (e) RT-PCR quantification of individual miRNAs in siRNA transfected HL-60 cells with or without ATRA treatment. $n . s$ - no significant difference; ${ }^{* * *} p<0.001$. (f) WBs showing PHLPP2 levels in control (NC) and C/EBP $\beta$ silenced HL-60 cells following exposure to $1 \mu \mathrm{M}$ ATRA for 3 days

The miR-17-92 cluster is frequently amplified in several lymphomas and in lung cancer, ${ }^{16,42}$ and aberrant overexpression of the miR-17-92 polycistron is detected in many cancers. ${ }^{43}$ Retinoblastoma-like 2 protein (p130, Rbl2), Cdk inhibitor p21CIP1, transforming growth factor $\beta 1$ (TGF $\beta 1$ ), proapoptotic Bcl-2 protein Bim, the tumor-suppressor PTEN and transcription factor E2F1 are some of the cluster's targets. ${ }^{14} \mathrm{~A}$ previous study on drug-resistant mantle cell lymphomas with an amplified oncomir-1 cluster suggested that the chemoresistance was mediated largely through PHLPP2 suppression, although this was not directly tested in the mantle cell lymphomas model. ${ }^{12}$ Our studies in AML offer the first direct evidence that the miR-17-92 cluster controls PHLPP2 protein levels through the 3'UTR of its mRNA.

The regulated expression of miR-17-92 across AML subtypes suggests a developmental role for these miRNAs. This cluster has already been implicated in the survival signal that promotes progression from the pro-B- to pre-B-cell stage during normal B-cell development, in part through its suppression of Bim protein expression. ${ }^{44}$ Downregulation of the miR-17-92 cluster is essential for induction of normal myeloid differentiation orchestrated by myeloid transcription factor PU.1. ${ }^{45}$ Thus, upregulation of the cluster could lead to a differentiation block in specific AML subtypes. Our studies 


\section{a}
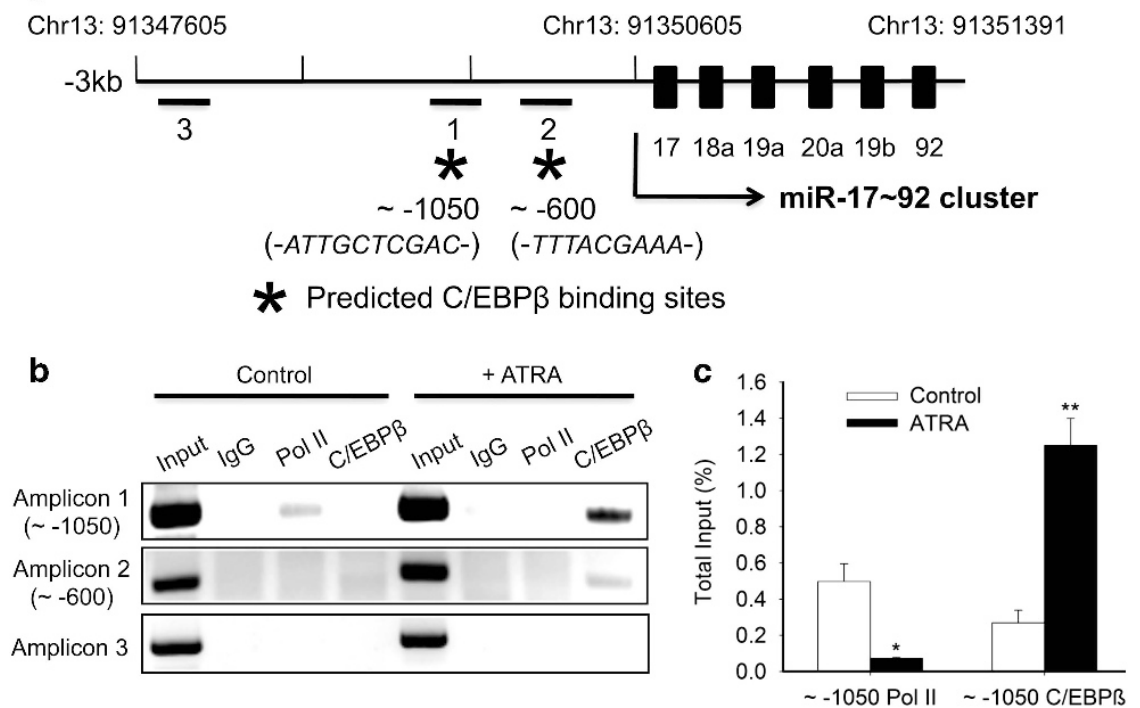

Figure $6 \mathrm{C} / \mathrm{EBP} \beta$ binds to the intronic promoter of the miR-17-92 cluster. (a) Schematic representation of the upstream region of miR-17-92 cluster (not to scale). Putative C/ $\mathrm{EBP} \beta$ binding sites are shown as asterisks and consensus sequences are italicized in parentheses. PCR amplicons 1,2 and 3 are shown as numbered lines. (b) HL-60 cells were treated with $1 \mu \mathrm{M}$ ATRA for 3 days and subjected to a ChIP assay to detect the interaction between RNA polymerase II (Pol II) or C/EBP $\beta$ with the amplicons1, 2 and 3 shown in a. (c) RT-PCR was performed to measure the levels of the binding of Pol II or C/EBP $\beta$ with amplicon 1 (containing the 1050 binding site) in HL-60 cells treated with $1 \mu \mathrm{M}$ ATRA for 3 days; ${ }^{*} p<0.05 ;{ }^{* *} p<0.01$

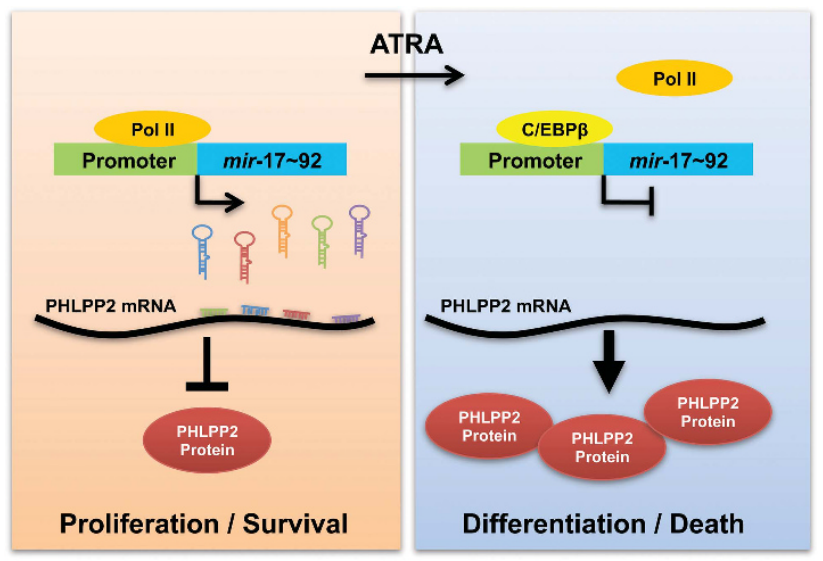

Figure 7 A model for regulation of tumor-suppressor phosphatase, PHLPP2, in AML cells. In unperturbed AML cells, RNA polymerase II binds to and activates the miR-17-92 cluster. These miRNAs (colored hairpins) bind to the 3'UTR of PHLPP2 and inhibit its translation. ATRA treatment leads to the upregulation of $\mathrm{C} / \mathrm{EBP} \beta$, which binds the miR-17-92 intronic upstream region distally, preventing RNA Polymerase II from binding and inhibiting transcription of the cluster. This releases the block on PHLPP2 translation allowing the phosphatase to accumulate in the cells and repress growth and proliferation through inactivation of key oncogenic substrates, such as S6K

suggest that increased expression of the miR-17-92 cluster is not controlled by $\mathrm{c}-\mathrm{MYC}$ or $\mathrm{E} 2 \mathrm{~F} 1 / 3$, transcription factors known to upregulate the cluster in solid tumors and in some $B$ lymphomas, ${ }^{22-24}$ although loss of a repressor in the PU.1 signaling pathway is not being ruled out. We also show that ATRA-induced activation of differentiation in HL-60 cells causes significant suppression of the miR-17-92 cluster
(Figures $4 \mathrm{~b}$ and e, Supplementary Figure S5D). The suppression and subsequent de-repression of miR-17-92 targets, including PHLPP2 (Figure 4a), are likely critical for mediating ATRA's differentiating effect. The increased sensitivity of PHLPP2 3'UTR 'sponge'-transfected cells to ATRA (Figures $4 \mathrm{f}$ and $\mathrm{g}$ ) support this possibility.

Our studies show that C/EBP $\beta$, an ATRA target, mediates the repression of the oncomir-1 cluster in HL-60 cells by interacting directly with a binding site in the intronic promoter of the miR-17-92 gene (Figure 6). Previous studies showed that transcription factors $\mathrm{C}-\mathrm{MYC}$ and E2F bind to the promoter region of the host gene, MIR17HG. ${ }^{22-24}$ In AML cells, neither c-MYC nor E2F silencing affected miR-17-92 expression, but C/EBP $\beta$ binding to the intronic promoter could repress the cluster, suggesting that transcriptional regulation of the miR-17-92 cluster in $A M L$ is independent of its host gene. C/EBP $\beta$ is a member of the C/EBP family of basic region/leucine zipper transcription factors, important for differentiation of liver, adipose tissue and hematopoietic cells. ${ }^{38}$ The C/EBP $\beta$ promoter contains binding sites for several transcription factors including RARa. $\mathrm{C} / \mathrm{EBP} \beta$ can promote either activation or repression of its target genes in a cell- and tissue-specific manner. ${ }^{38,39}$ It is one of the major proteins induced in response to ATRA, and is essential for granulocytic differentiation. We show that the ATRA-induced reduction in miR-17-92 levels requires the presence of C/EBP $\beta$ (Figure 5). The initial drop in miR-17-92 levels in untreated HL-60 cells expressing C/EBP $\beta$ siRNA compared with controls suggests that the transcription factor may function as an activator of miR-17-92 at low concentrations. However, untreated levels were unaffected by the addition of ATRA (Figure $5 d$ ). C/EBP $\beta$ has been attributed a tumor-promoting role in breast and prostate cancer $^{46-48}$ and shown to be a negative regulator of miR-145, 
a tumor-suppressor miRNA often downregulated in breast cancer. $^{49}$

Interestingly, C/EBP $\beta$ that is upregulated in ATRA-treated cells can also bind and activate the promoter for master hematopoietic transcription factor PU.1. ${ }^{50}$ Suppression of PU.1 is critical to the maturation block at the promyelocytic stage in APL, and restoration of its expression by ATRA was suggested to be a major mechanism leading to granulocytic differentiation. The significant reduction in miR-17-92 levels and in the primary transcript in ATRA-treated HL-60 cells (Figure $4 \mathrm{e}$ and Supplementary Figure S4B) supports the possibility that C/EBP $\beta$ suppresses miR-17-92 via two pathways - indirectly through induction of PU.1 expression, where it functions as an activator, and more efficiently, through direct interaction with the miR-17-92 promoter, as we have demonstrated, where it functions as a repressor.

Cancer cells have evolved multiple regulatory pathways to suppress PHLPP2 expression or activity. However, despite growing interest in their potential therapeutic value, investigations of the PHLPP phosphatases have focused largely on solid tumors. Our group is particularly interested in mechanisms underlying PHLPP2 control in leukemia. Posttranscriptional inhibition by the oncomir-1 cluster, identified here, is just one of multiple cell type specific, regulatory mechanisms for restraining the tumor-suppressor phosphatase. Although PHLPP2 is reduced or absent in some AML, the protein is constitutively expressed at high levels and controlled through post-translational modifications in other leukemias (unpublished). Investigations to identify posttranslational mechanisms that inactivate PHLPP2 in these leukemias are underway. Overall, our studies establish the significance of PHLPP2 regulation during AML development and terminal differentiation and provide a foundation for future studies aimed at therapeutic targeting of the phosphatase, either directly or via C/EBP $\beta$ and/or miR-17-92.

\section{Materials and Methods}

Cell lines, cell culture, antibodies, plasmid constructs and chemicals are described under Supplemental Methods.

mRNA isolation and RT-PCR. mRNA was extracted from $1 \times 10^{6}-5 \times 10^{6}$ suspension leukemia cells with TRIZOL reagents (Invitrogen, Carlsbad, CA, USA) and CDNA was synthesized from 500 to $800 \mathrm{ng}$ mRNA template using the DyNAamo cDNA Synthesis Kit (Thermo Scientific, Waltham, MA, USA), according to the manufacturer's protocols. The cDNA was amplified through PCR primers (see Supplementary Information for primers). The PCR products were run on a $2 \%$ agarose gel, stained with ethidium bromide and visualized under UV light.

miRNA quantification. Total miRNAs were extracted from cells using mirVana miRNA isolation kit (Life Technologies, Grand Island, NY, USA). cDNA was synthesized by reverse transcription using the miScript II RT kit (Qiagen). Finally, miScript SYBR Green PCR kit (Qiagen, Hilden, Germany) was used to quantify the levels of individual miRNA in miR-17-92 cluster. The miRNA levels were normalized to an U6 internal control. Except for the miR-17-92 cluster measured in leukemia cell lines for Figure $2 b$, which was performed with the MiR-17-92 cluster plate assay kit (Signosis Inc. Durham, NC, USA), all measurements of miR-17-92 cluster levels were performed using the miScript miRNA PCR assay (Qiagen).

Cell transfection. Transfections of PHLPP2 3'UTR constructs into U937 and HL-60 cells were performed using a Bio-Rad Electroporator as described previously ${ }^{51}$ or through the Neon Transfection System (Invitrogen) using the manufacturer's protocol. FuGENE Transfection Reagent (Promega, Madison, WI, USA) was used for HEK293 cell transfections according to the manufacturer's protocol. Negative control and c-myc, E2F1, E2F3, C/EBP $\beta$ siRNAs (Santa Cruz Biotechnology, Santa Cruz, CA, USA) and the siRNA were introduced into $\mathrm{HL}-60$ and U937 cells using the Neon System.

Western blotting. For western blotting, cells were lysed in RIPA buffer $(50 \mathrm{mM}$ Tris- $\mathrm{HCl}(\mathrm{pH} 7.5), 150 \mathrm{mM} \mathrm{NaCl}, 0.5 \% \mathrm{v} / \mathrm{v}$ sodium deoxycholate, $1 \% \mathrm{v} / \mathrm{v}$ Nonidet $\mathrm{P}-40,0.1 \% \mathrm{SDS}$ ) supplemented with protease and phosphatase inhibitor cocktails. Lysates were resolved by SDS-PAGE and transferred to nitrocellulose membrane. The blots were incubated with specific antibodies and chemiluminescent reactions were carried out using the Pierce ECL 2 kit (Thermo Scientific). Blots were stripped for reuse by washing for $30 \mathrm{~min}$ in TBS-T buffer (pH 2.5-3.0).

ChIP assay. ChIP was performed using the Millipore ChIP Assay Kit according to the manufacturer's protocol EMD Millipore, Darmstadt, Germany. Briefly, 37\% formaldehyde-cross-linked $\mathrm{HL}-60$ cells were collected, lysed, sonicated to approximately 500-bp segments and subjected to immunoprecipitation with RNA polymerase II, C/EBP $\beta$ antibodies or IgG control antibody (Santa Cruz Biotechnology). Immunocomplexes were collected on protein A/G agarose beads blocked with salmon sperm DNA and eluted. Cross-links were reversed by incubating at $65^{\circ} \mathrm{C}$ overnight. PCR was performed to amplify different portions of the miR-17-92 promoter (primer sequences are in Supplemental Information). PCR products were run on a $2 \%$ agarose gel, stained with ethidium bromide and visualized under UV light. For quantification of fold enrichment in Pol II or C/EBP $\beta$ binding, $5 \mathrm{ng}$ of total chromatin was used as control and quantitative real-time PCR was performed using SYBR Green.

Statistics. All averages are presented as mean \pm S.E. Student's two-tailed test were used for all analyses: ${ }^{\star} P<0.05 ;{ }^{\star \star} P<0.01 ;{ }^{\star \star \star} P<0.001$.

\section{Conflict of Interest}

The authors declare no conflict of interest.

Acknowledgements. For valuable technical advice, we thank Lihua Li and Jyotika Varshney from the Subramanian laboratory. This work was supported by NIH grant R01 CA157971 to AK and American Cancer Society grant RSG-13-381-01 to SS, NIHT32 (CA009138) training fellowships to EAH and JMB, F31 award (CA177119) to $\mathrm{EAH}$, and a doctoral dissertation award to XHL.

1. McConnell JL, Wadzinski BE. Targeting protein serine/threonine phosphatases for drug development. Mol Pharmacol 2009; 75: 1249-1261.

2. Gao T, Furnari F, Newton AC. PHLPP: a phosphatase that directly dephosphorylates Akt, promotes apoptosis, and suppresses tumor growth. Mol Cell 2005; 18: 13-24.

3. Warfel NA, Newton AC. Pleckstrin homology domain leucine-rich repeat protein phosphatase (PHLPP): a new player in cell signaling. J Biol Chem 2012; 287: 3610-3616.

4. Brognard J, Newton AC. PHLiPPing the switch on Akt and protein kinase $\mathrm{C}$ signaling. Trends Endocrinol Metab 2008; 19: 223-230.

5. Brognard J, Sierecki E, Gao T, Newton AC. PHLPP and a second isoform, PHLPP2, differentially attenuate the amplitude of Akt signaling by regulating distinct Akt isoforms. Mol Cell 2007; 25: 917-931.

6. Liu J, Stevens PD, Li X, Schmidt MD, Gao T. PHLPP-mediated dephosphorylation of S6K1 inhibits protein translation and cell growth. Mol Cell Biol 2011; 31: 4917-4927.

7. Qiao M, Wang Y, Xu X, Lu J, Dong Y, Tao W et al. Mst1 is an interacting protein that mediates PHLPPs' induced apoptosis. Mol Cell 2010; 38: 512-523.

8. O'Neill AK, Niederst MJ, Newton AC. Suppression of survival signalling pathways by the phosphatase PHLPP. FEBS J 2013; 280: 572-583.

9. Liu J, Stevens PD, Gao T. mTOR-dependent regulation of PHLPP expression controls the rapamycin sensitivity in cancer cells. J Biol Chem 2011; 286: 6510-6520.

10. Cai J, Fang L, Huang Y, Li R, Yuan J, Yang Y et al. miR-205 targets PTEN and PHLPP2 to augment AKT signaling and drive malignant phenotypes in non-small cell lung cancer. Cancer Res 2013; 73: 5402-5415.

11. Liao WT, Li TT, Wang ZG, Wang SY, He MR, Ye YP et al. microRNA-224 promotes cell proliferation and tumor growth in human colorectal cancer by repressing PHLPP1 and PHLPP2. Clin Cancer Res 2013; 19: 4662-4672.

12. Rao $\mathrm{E}$, Jiang $\mathrm{C}$, Ji M, Huang $\mathrm{X}$, lqbal J, Lenz $\mathrm{G}$ et al. The miRNA-17 92 cluster mediates chemoresistance and enhances tumor growth in mantle cell lymphoma via PI3K/AKT pathway activation. Leukemia 2012; 26: 1064-1072. 
13. He L, Thomson JM, Hemann MT, Hernando-Monge E, Mu D, Goodson S et al. A microRNA polycistron as a potential human oncogene. Nature 2005; 435: 828-833.

14. Olive V, Li Q, He L. mir-17-92: a polycistronic oncomir with pleiotropic functions. Immunol Rev 2013; 253: 158-166.

15. Inomata M, Tagawa H, Guo YM, Kameoka Y, Takahashi N, Sawada K. MicroRNA-17-92 down-regulates expression of distinct targets in different B-cell lymphoma subtypes. Blood 2009; 113: 396-402.

16. Hayashita $Y$, Osada H, Tatematsu $Y$, Yamada H, Yanagisawa $K$, Tomida $S$ et al. A polycistronic microRNA cluster, miR-17-92, is overexpressed in human lung cancers and enhances cell proliferation. Cancer Res 2005; 65: 9628-9632.

17. Lu J, Getz G, Miska EA, Alvarez-Saavedra E, Lamb J, Peck D et al. MicroRNA expression profiles classify human cancers. Nature 2005; 435: 834-838.

18. Mogilyansky E, Rigoutsos I. The miR-17/92 cluster: a comprehensive update on its genomics, genetics, functions and increasingly important and numerous roles in health and disease. Cell Death Differ 2013; 20: 1603-1614.

19. Nagel S, Venturini L, Przybylski GK, Grabarczyk P, Schmidt CA, Meyer $C$ et al. Activation of miR-17-92 by NK-like homeodomain proteins suppresses apoptosis via reduction of E2F1 in T-cell acute lymphoblastic leukemia. Leuk Lymphoma 2009; 50: 101-108.

20. Tagawa $\mathrm{H}$, Seto M. A microRNA cluster as a target of genomic amplification in malignant lymphoma. Leukemia 2005; 19: 2013-2016.

21. Wang F, Li T, Zhang B, Li H, Wu Q, Yang $L$ et al. MicroRNA-19a/b regulates multidrug resistance in human gastric cancer cells by targeting PTEN. Biochem Biophys Res Commun 2013; 434: 688-694.

22. O'Donnell KA, Wentzel EA, Zeller KI, Dang CV, Mendell JT. c-Myc-regulated microRNAs modulate E2F1 expression. Nature 2005; 435: 839-843.

23. Sylvestre Y, De Guire V, Querido E, Mukhopadhyay UK, Bourdeau V, Major F et al. An E2F/ miR-20a autoregulatory feedback loop. J Biol Chem 2007; 282: 2135-2143.

24. Woods $\mathrm{K}$, Thomson JM, Hammond SM. Direct regulation of an oncogenic micro-RNA cluster by E2F transcription factors. J Biol Chem 2007; 282: 2130-2134.

25. Yan HL, Xue G, Mei Q, Wang YZ, Ding FX, Liu MF et al. Repression of the miR-17-92 cluster by p53 has an important function in hypoxia-induced apoptosis. EMBO J 2009; 28 : 2719-2732.

26. Lowenberg B, Downing JR, Burnett A. Acute myeloid leukemia. N Engl J Med 1999; 341 : 1051-1062.

27. Cerami E, Gao J, Dogrusoz U, Gross BE, Sumer SO, Aksoy BA et al. The cBio cancer genomics portal: an open platform for exploring multidimensional cancer genomics data. Cancer Discov 2012; 2: 401-404.

28. Gao J, Aksoy BA, Dogrusoz U, Dresdner G, Gross B, Sumer SO et al. Integrative analysis of complex cancer genomics and clinical profiles using the cBioPortal. Sci Signal 2013; 6 pl1.

29. Li X, Stevens PD, Yang H, Gulhati P, Wang W, Evers BM et al. The deubiquitination enzyme USP46 functions as a tumor suppressor by controlling PHLPP-dependent attenuation of Akt signaling in colon cancer. Oncogene 2013; 32: 471-478.

30. Campone M, Noel B, Couriaud C, Grau M, Guillemin Y, Gautier F et al. c-Myc dependent expression of pro-apoptotic Bim renders HER2-overexpressing breast cancer cells dependent on anti-apoptotic Mcl-1. Mol Cancer 2011; 10: 110.

31. Breitman TR, Selonick SE, Collins SJ. Induction of differentiation of the human promyelocytic leukemia cell line (HL-60) by retinoic acid. Proc Natl Acad Sci USA 1980; 77 : 2936-2940.
32. Cull EH, Altman JK. Contemporary treatment of APL. Curr Hematol Malig Rep 2014; 9: 193-201.

33. Degos L, Dombret H, Chomienne C, Daniel MT, Miclea JM, Chastang C et al. All-transretinoic acid as a differentiating agent in the treatment of acute promyelocytic leukemia. Blood 1995; 85: 2643-2653.

34. Gallagher R, Collins S, Trujillo J, McCredie K, Ahearn M, Tsai S et al. Characterization of the continuous, differentiating myeloid cell line $(\mathrm{HL}-60)$ from a patient with acute promyelocytic leukemia. Blood 1979; 54: 713-733.

35. Billottet C, Banerjee L, Vanhaesebroeck B, Khwaja A. Inhibition of class I phosphoinositide 3kinase activity impairs proliferation and triggers apoptosis in acute promyelocytic leukemia without affecting ATRA-induced differentiation. Cancer Res 2009; 69: 1027-1036.

36. Takitani $\mathrm{K}$, Koh M, Zhu CL, Inoue A, Kuno T, Tanoue $\mathrm{H}$ et al. Expression of retinoic acid receptor-target genes during retinoic acid therapy for acute promyelocytic leukemia. Leukemia 2003; 17: 646-648.

37. Zhang JW, Wang JY, Chen SJ, Chen Z. Mechanisms of all-trans retinoic acid-induced differentiation of acute promyelocytic leukemia cells. J Biosci 2000; 25: 275-284.

38. Duprez E, Wagner K, Koch H, Tenen DG. C/EBPbeta: a major PML-RARA-responsive gene in retinoic acid-induced differentiation of APL cells. EMBO J 2003; 22: 5806-5816.

39. Huber R, Pietsch D, Panterodt T, Brand K. Regulation of C/EBPbeta and resulting functions in cells of the monocytic lineage. Cell Signal 2012; 24: 1287-1296.

40. Monteys AM, Spengler RM, Wan J, Tecedor L, Lennox KA, Xing Y et al. Structure and activity of putative intronic miRNA promoters. RNA 2010; 16: 495-505.

41. Osada S, Yamamoto $H$, Nishihara T, Imagawa M. DNA binding specificity of the CCAAT/ enhancer-binding protein transcription factor family. J Biol Chem 1996; 271: 3891-3896.

42. Ota A, Tagawa H, Karnan S, Tsuzuki S, Karpas A, Kira $S$ et al. Identification and characterization of a novel gene, $\mathrm{C} 13$ orf25, as a target for 13q31-q32 amplification in malignant lymphoma. Cancer Res 2004; 64: 3087-3095.

43. Garofalo M, Croce CM. microRNAs: master regulators as potential therapeutics in cancer. Annu Rev Pharmacol Toxicol 2011; 51: 25-43.

44. Ventura A, Young AG, Winslow MM, Lintault L, Meissner A, Erkeland SJ et al. Targeted deletion reveals essential and overlapping functions of the miR-17 through 92 family of miRNA clusters. Cell 2008; 132: 875-886.

45. Alemdehy MF, Erkeland SJ. MicroRNAs: key players of normal and malignant myelopoiesis. Curr Opin Hematol 2012; 19: 261-267.

46. Bundy LM, Sealy L. CCAAT/enhancer binding protein beta (C/EBPbeta)-2 transforms normal mammary epithelial cells and induces epithelial to mesenchymal transition in culture. Oncogene 2003; 22: 869-883.

47. Kim MH, Fields J. Translationally regulated C/EBP beta isoform expression upregulates metastatic genes in hormone-independent prostate cancer cells. Prostate 2008; 68: 1362-1371.

48. Zahnow CA, Younes P, Laucirica R, Rosen JM. Overexpression of C/EBPbeta-LIP, a naturally occurring, dominant-negative transcription factor, in human breast cancer. J Natl Cancer Inst 1997; 89: 1887-1891.

49. Sachdeva M, Liu Q, Cao J, Lu Z, Mo YY. Negative regulation of miR-145 by C/EBP-beta through the Akt pathway in cancer cells. Nucleic Acids Res 2012; 40: 6683-6692.

50. Mueller BU, Pabst T, Fos J, Petkovic V, Fey MF, Asou $\mathrm{N}$ et al. ATRA resolves the differentiation block in $\mathrm{t}(15 ; 17)$ acute myeloid leukemia by restoring PU.1 expression. Blood 2006; 107: 3330-3338.

51. Lowman XH, McDonnell MA, Kosloske A, Odumade OA, Jenness C, Karim CB et al. The proapoptotic function of Noxa in human leukemia cells is regulated by the kinase Cdk5 and by glucose. Mol Cell 2010; 40: 823-833.

\section{Supplementary Information accompanies this paper on Cell Death and Differentiation website (http://www.nature.com/cdd)}

